\title{
Food \& Nutrition Research towards 2013 and onwards
}

$\mathrm{T}$ his is my first editorial as the new Editor-in-Chief for Food \& Nutrition Research (FNR). This editorial contains both good and sad news (but this is how life is so why would a scientific journal be any different?).

To start with the sad news: Professor Nils-Georg Asp, until recently Editor-in-Chief for $F N R$, passed away in early June this summer, right before the Nordic Nutrition Conference in Iceland. It was four years ago that Nils-Georg learned he had prostate cancer. While working through his illness he never lost his positive outlook or his enthusiasm for the things he cared about. FNR was among these things. Indeed, from the outside, cancer seemed to be only a minor obstacle in his way. Last year he nevertheless chose to step down as Editor-in-Chief, although he insisted on continuing as a section editor. This made my move to the Editor-in-Chief post very smooth and easy.

The last time I met Nils-Georg was in January in Lund, Sweden. During a meeting lasting several hours and over a good lunch, we discussed many things, but most of all the future of $F N R$. Even after that meeting we continued to exchange ideas by email. On June $1^{\text {st }}$ I had just finished a couple of hours' work with manuscripts submitted to $F N R$ when I received the message that Nils-Georg was no longer with us. Though not unexpected the news left me feeling very sad and at a loss for words for a long while. At the same time I was happy that this piece of information had reached me precisely as I was working with something Nils-Georg cared about so much.

With this editorial I would like to honour the memory of Professor Nils-Georg Asp and share with readers my personal commitment to continue to develop $F N R$ in a way that would make Nils-Georg proud.

What can readers and authors expect from $F N R$ in 2013 and onwards? The journal has taken many major strides in recent years. We will continue to build on these achievements to create a high-quality open access journal focusing on food and human nutrition. Submissions addressing food and health based on quantitative or qualitative methodologies are welcome. We will be working to improve and speed up the review process. This includes a review of the $F N R$ electronic platform, the roles and division of labour between Editor-in-Chief and Section Editors, and guaranteeing a swift yet rigorous peer review of submitted papers. I also urge our readers and authors to send us ideas and suggestions on how to improve our processes.

$F N R$ has published supplements and special clusters of articles from conferences or specific working groups. We will continue to welcome such publications moving forward, and are pleased to have been selected as the publication channel for the Nordic Nutrition Recommendations (1) that are currently being developed. This work has involved a systematic review, including a quality assessment, of all pertinent studies and a final grading of the overall evidence, which has been applied for selected nutrients and topics. This approach has also been used as a basis for issuing food-based dietary guidelines. These systematic reviews provide the basis for the working group to formulate final recommendations. FNR will publish these reviews in addition to other pertinent background papers. Two reports are already in the making: The first report focusing on sugar and health is written by Emily Sonestedt et al. (2) and was published this month (July). By using prospective cohort studies published in the years 2000-2011, the authors conclude that sugar-sweetened beverages probably increase the risk of type-2 diabetes. For related metabolic risk factors, cardiovascular disease, or all-cause mortality and other types of sugars, too few studies were available to draw conclusions. While the results may be somewhat disappointing for those who would like to have more compelling evidence against sugar, they illustrate the very critical way of making evidence-based conclusions. The reporting of the reviews is, fortunately, very detailed and open and therefore our readers will be able to see how the authors have reached their conclusions.

The second review, at proof-reading status at the time of writing this editorial, is related to prevention of weight gain by macronutrients and foods (3). This issue is as heavily debated and discussed as that on sugar and health. I am certain that these two and many others of the NNR reviews to come will be highly appreciated by both the scientific communities and other groups working with new dietary recommendations.

Mikael Fogelholm, Professor in Nutrition University of Helsinki, Department of Food and Environmental Sciences Editor-in-Chief 


\section{References}

1. NNR5 working group. Revision of the Nordic Nutrition Recommendations. http://www.slv.se/en-gb/Startpage-NNR/. 2012. (accessed 30 July 2012).

2. Sonestedt E, Øverby NC, Laaksonen DE, Birgisdottir BE. Does high sugar consumption exacerbate cardiometabolic risk factors and increase the risk of type 2 diabetes and cardiovascular disease? Food \& Nutrition Research 2012. 56: 19104 - http:// dx.doi.org/10.3402/fnr.v56i0.19104.
3. Fogelholm M, Anderssen S, Gunnarsdottir I, Lahti-Koski M. Dietary macronutrients and food consumption as determinants of long-term weight change in adult populations: a systematic literature review. Food \& Nutrition Research 2012. 56: 19103 http://dx.doi.org/10.3402/fnr.v56i0.19103. 